Special issue of the International Conference on Computational and Experimental Science and Engineering (ICCESEN 2014)

\title{
Prediction of Sheet Drawing Characteristics with Square Drawbead Elements Using Response Surface Methodology
}

\author{
A.E. TiRYAKI*, R. KOZAn, And N.G. AdAR \\ Sakarya University, Mechanical Engineering Department, Sakarya, Turkey
}

\begin{abstract}
Drawbeads are often used in the sheet metal forming processes to provide a better control of the material flow into the die cavity. The drawbead restraint force (DBRF) and the exit thickness are two important sheet drawing characteristics to be determined for the selection and installation of the drawbead elements. This study presents the effects of drawbead geometry and sheet material on drawbead restraining force and thinning. Mathematical correlation between the drawbead geometry, sheet material and drawing characteristics was investigated by using Response Surface Methodology (RSM), which is a global approximation method ideally suited for solving highly nonlinear optimization problems. The proposed response surface model for DBRF and thinning showed a good correlation with the experimental data available in the literature. RSM could be considered as an alternative and practical technique to evaluate the sheet drawing characteristics. The method can also be applied to other sheet metal forming issue.
\end{abstract}

DOI: 10.12693/APhysPolA.128.B-344

PACS: 02.60.Ed, 81.20.Hy, 02.50.r

\section{Introduction}

The drawbead elements generate a stable tension opposite to the sheet drawing direction by imposing a series of local bending, unbending (straightening) and reverse bending deformations on the sheet. The tension force required to pull the sheet through a drawbead element is called as the drawbead restraining force (DBRF). During the sliding process through a drawbead, the sheet metal experiences some reduction in its thickness as well as work hardens. From the process design point of view, the magnitude of the restraining force and the drawbead exit thickness are two important sheet drawing characteristics to be determined for the selection and installation of the drawbead elements. An accurate prediction of the sheet drawing characteristics with drawbead elements is crucial in the forming process design since an improper design may lead to unacceptable stamping failures that may be both costly and time consuming if corrected in the workshop trial phase [1].

In the literature, the research work has been done on drawbeads both in experiment and simulation. Nine [2] conducted experiments used the round type drawbead elements to investigate the various parameters affecting the restraining forces in the bead. Wang [3] developed the modeling technique for analytical investigation on the subject. Wang and Shah [4] evaluated the effects of drawbead dimensions and friction coefficients. Kojima [5] presented that drawbead effects for controlling draw-ins of a sheet are simplified to the restraining force working at a drawbead position. Demeri [6]

*corresponding author; e-mail: aysune@sakarya.edu.tr assessed the influence of material properties, drawbead penetration and lubricating condition on the sheet flow. Sunaga et al. [7] proposed an efficient method to determine the DBRF, which was calculated only from the contact angle between the sheet and drawbead, for arbitrary drawbead dimensions without real and experiment. Keum et al. [8] proposed expert drawbead model which provides the drawing characteristics of the drawbead used in the finite-element analysis of sheet metal forming process to overcome the limitations of previous equivalent drawbead model positioned in the direction of normal to the sheet movement. Naceur et al. [9] presented an optimization procedure of drawbead restraining forces in order to improve the sheet metal formability in deep drawing process. Firat [1] developed an analytical model for the sectional deformation analysis of automotive sheets passing through a drawbead element. Han et al. [10] suggested a computational inverse technique to identify geometric parameters of drawbead using a NN combined with GA. The sheet drawing characteristics of a dual-phase steel (DP600) through a round drawbead were determined by Livatyali et al. [11] using strip drawing tests. A new design methodology for complex sheet metal stamping processes was presented by Ingarao and Lorenzo [12]. It is based on the integration among numerical simulations, response surface methodologies and multi-objective optimization techniques (Pareto optimal solution search techniques). In approach presented by Donglai et al. [13], the adaptive response surface method and response surface method are introduced into sheet metal forming to optimize the process variables and predict the performance tolerance caused by the fluctuation of noise factors.

The main aim of the present study is to investigate mathematical correlation between the drawbead 
geometry, sheet material and drawing characteristics generated by square type drawbead elements in sheet metal forming by using the RSM. The model predictions in terms of the DBRF and thinning are compared with experimental data available in the literature [14].

\section{Experimental setup}

A brief description of "Drawbead Restraining Force Tests" in A/SP-Enhanced Formability Project carried out by Auto/Steel Partnership (A/SP) will be presented in this section. The objective of this stage is to document the drawing characteristics of sheet metals with a square drawbead element. Drawbead restraining force tests were carried out to determine the level of force required to pull a blank through the drawbead for different bead configuration (i.e. for a given material/lubrication combination). A drawbead restraining force apparatus was designed constructed at Industrial Research and Developed Institute (IRDI) in Midland, Canada. It is comprised of hydraulic cylinder mounted on a rigid frame that can be bolted to the side of hydraulic press. This hydraulic cylinder and hydraulic power unit enabled the DBRF apparatus to easily pull a $254 \mathrm{~mm}$ wide blank through the A/SP channel draw die showed in Fig. 1a. Drawbead inserts were removed from the LHS of the die (insert $\mathrm{C}$ and D) and flat inserts (no beads) were installed in their place. As a blank was pulled through the drawbeads in the closed die, the pulling force obtained from load cells and displacements of the clamp obtained from a wire transducer were recorded with data acquisition software. In project variable penetration (from approximately $20 \%$ to $100 \%$ penetration) drawbead inserts were used. The radii of the bead and contra-bead entry and exit shoulders are all equal to $4 \mathrm{~mm}$ and a fixed clearance of $1.4 \mathrm{~mm}$ is used for all materials (Fig. 1b). A prelube type lubricant (61-MAL-HCL-1 from Quaker Chemical Corp.) with a nominal friction coefficient of 0.12 is used in the drawing tests [14]. The details of the workshop procedures in the channel drawing tests and drawbead restraining force tests may be found in Ref. [14].

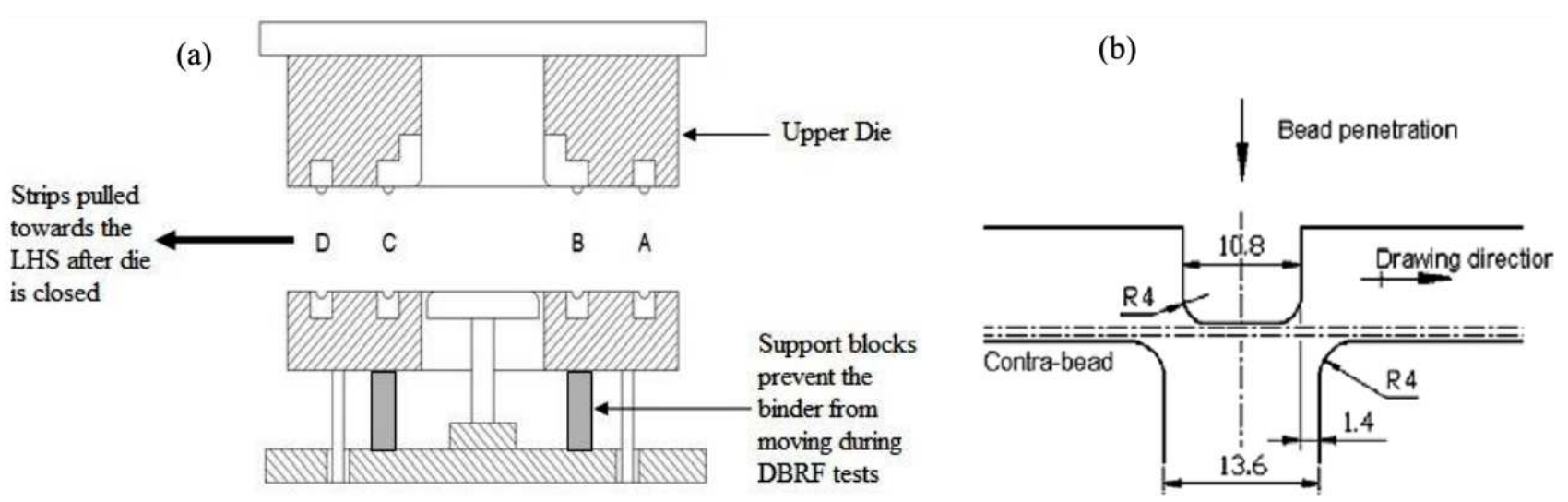

Fig. 1. (a) Sketch of the channel draw die, (b) Schematics showing the cross-section of the square drawbead [14].

\section{Response surface model}

Response surface methodology is an empirical statistical modeling technique used for multiple regression analysis. RSM is used in the development of an adequate functional relationship (or multivariate equations) between a response of interest and a number of associated input variables called as independent variables. In general, this functional relationship is explained by empirical first-order or second-order polynomial models as follows:

$$
Y=B_{0}+\sum_{i=1}^{k} B_{i} X_{i}+\sum_{i=1}^{k} B_{i i} X_{i}^{2}+\sum_{i=1}^{k-1} \sum_{j=2}^{k} B_{i j} X_{i} X_{j},
$$

where $Y$ is the predicted response, $X$ real value of the independent variable, $B_{0}$ a constant, $B_{i}$ linear coefficient, $B_{i i}$ quadratic coefficient, $B_{i j}$ interaction coefficient, $k$ is the number of factors.

In this study, first-order and different types of secondorder polynomial models was evaluated. The studied parameters as independent variables were the sheet thickness $\left(t_{0}\right)$, material properties $(\mathrm{M})$ and \% penetration $(P)$ and the predicted responses as dependent variables were the $\operatorname{DBRF}\left(Y_{1}\right)$ and thinning $\left(Y_{2}\right)$.

The term in the material properties, M, can be defined using the Hills's yield criteria and associated flow rule the expressions for equivalent stress and strain [15]

$$
M=K \frac{(1+r)^{n+1}}{(\sqrt{1+2 r})^{n+1}} .
$$

The properties of sheet material used in the drawbead tests are also given in Table I. The sheet materials are aluminum-killed draw quality steel (AKDQ), highstrength low-allow steel (HSLA), bake hardening steel and dualphase steel (DP600).

The first and second-order regression equations obtained for the DBRF $\left(Y_{1}\right)$ and thinning $\left(Y_{2}\right)$ are presented in Table II. 


\section{TABLE I}

The properties of sheet material in the drawbead tests.

\begin{tabular}{c|c|c|c|c|c|c}
\hline \hline & \multicolumn{2}{|c|}{ AKDQ-CR } & HSLA-HDG & HSLA-CR & BH210-EG & DP600-HDG \\
\hline$t_{0}[\mathrm{~mm}]$ & 0.716 & 1.198 & 0.787 & 1.168 & 0.780 & 1.180 \\
$K[\mathrm{MPa}]$ & 559.4 & 543.9 & 736.1 & 761.6 & 548 & 936.9 \\
$n$ & 0.212 & 0.209 & 0.168 & 0.149 & 0.156 & 0.136 \\
$r$ & 1.702 & 1.652 & 1.054 & 1.057 & 1.546 & 1.125
\end{tabular}

TABLE II

The properties of sheet material in the drawbead tests.

\begin{tabular}{|c|c|c|c|}
\hline regression & formulae & $R^{2}$ & $R M S E$ \\
\hline \multirow{2}{*}{ linear } & $Y_{1}=-355.691+291.101 t_{0}+0.132 M+1.894 P$ & 0.8239 & 42.149 \\
\hline & $Y_{2}=-0.1423+0.2193 t_{0}-0.0000839 M+0.0013 P$ & 0.7879 & 0.0302 \\
\hline \multirow{2}{*}{$\begin{array}{c}\text { pure } \\
\text { quadratic }\end{array}$} & $Y_{1}=-691.411+372.375 t_{0}+0.726 M+3.931 P-49.232 t_{0}^{2}-0.000323 M^{2}-0.0177 P^{2}$ & 0.8633 & 37.3119 \\
\hline & $Y_{2}=-5416+0.75 t_{0}+0.000244 M+0.002 P-0.2757 t_{0}^{2}-0.000000182 M^{2}-0.0000059 P^{2}$ & 0.8061 & 0.0297 \\
\hline \multirow{2}{*}{ interaction } & $Y_{1}=143.8775-107.3077 t_{0}-0.1658 M-4.5024 P+0.1509 t_{0} M+4.8369 t_{0} P+0.0024 M P$ & 0.9733 & 16.8064 \\
\hline & $Y_{2}=-0.069+0.0692 t_{0}+0.000112 M-0.0017 P-0.000123 t_{0} M+0.0043 t_{0} P-0.000001018 M P$ & 0.9791 & 0.0097 \\
\hline \multirow{2}{*}{$\begin{array}{c}\text { Full } \\
\text { Quadratic }\end{array}$} & $\begin{array}{c}Y_{1}=-91.6481-516.607 t_{0}+0.7486 M-3.2855 P+0.6178 t_{0} M+4.3321 t_{0} P+0.0026 M P \\
+33.3512 t_{0}^{2}-0.000791 M^{2}-0.0085 P^{2}\end{array}$ & 0.9919 & 9.4943 \\
\hline & $\begin{array}{c}Y_{2}=-0.2074+0.0976 t_{0}+0.000415 M-0.002 P+0.000109 t_{0} M+0.0044 t_{0} P-0.00000106 M P \\
-0.1093 t_{0}^{2}-0.000000309 M^{2}+0.00000177 P^{2}\end{array}$ & 0.9843 & 0.0087 \\
\hline
\end{tabular}

TABLE III

Validation data set and RSM predictions.

\begin{tabular}{c|c|c|c|c|c|c}
\hline \hline Material & Sheet thickness & Bead penetration & \multicolumn{2}{|c|}{ DBRF [N/mm] } & \multicolumn{2}{c}{ Thinning [mm] } \\
\cline { 3 - 7 } & {$\left[t_{0}\right]$} & {$[\%]$} & Experimental & RSM & Experimental & RSM \\
\hline AKDQ-CR & 0.716 & 90.62 & 100.86 & 99.59 & 0.05226 & 0.0495 \\
AKDQ-CR & 1.198 & 64.58 & 213.46 & 215.75 & 0.16650 & 0.1550 \\
HSLA-HDG & 0.787 & 45.31 & 89.69 & 90.00 & 0.03148 & 0.0313 \\
HSLA-CR & 1.168 & 35.17 & 175.32 & 169.50 & 0.06700 & 0.0740 \\
BH210-EG & 0.780 & 102.71 & 119.00 & 115.50 & 0.08346 & 0.0900 \\
DP600-HDG & 1.180 & 64.78 & 277.10 & 281.00 & 0.11328 & 0.1122
\end{tabular}

\section{Results}

As indicated in Table II, the fits of the regression models were evaluated by the determination coefficients $\left(R^{2}\right)$ and root mean squared error $(R M S E)$ and full quadratic model which is a second order response model shows a good correlation with the experimental data. The coefficients of determination indicated that the $99.19 \%$ and $98.43 \%$ of the total variation could be explained by the model equation obtained from full quadratic model for the DBRF and thinning, respectively.

As shown Fig. 2a, The DBRF increases as the sheet thickness, material properties $(\mathrm{M})$ values and \% penetration increases. For the cases studied it is possible to verify that the DBRF increases linearly with respect to sheet thickness but $M$ is not linear. It can be seen from the plots shown in Fig. $2 \mathrm{~b}$ that the increase in sheet thickness and \%penetration caused a increase in the thinning.
However thinning decreases as material properties (M) values increases.

Full quadratic models have been validated with the experimental data available in the literature [14]. Thus, it was decided to test response surface models using completely unseen data. The validation data sets and RSM predictions are given in Table III. RSM based models fitted the experimental data with an excellent accuracy.

\section{Conclusion}

Response surface model defined functional relationship between the drawbead geometry, sheet material and drawing characteristics was suggested in this study. The proposed model for DBRF and thinning showed a good correlation with the experimental data available in the literature. RSM could be considered as an alternative, practical and fast technique for dealing with 


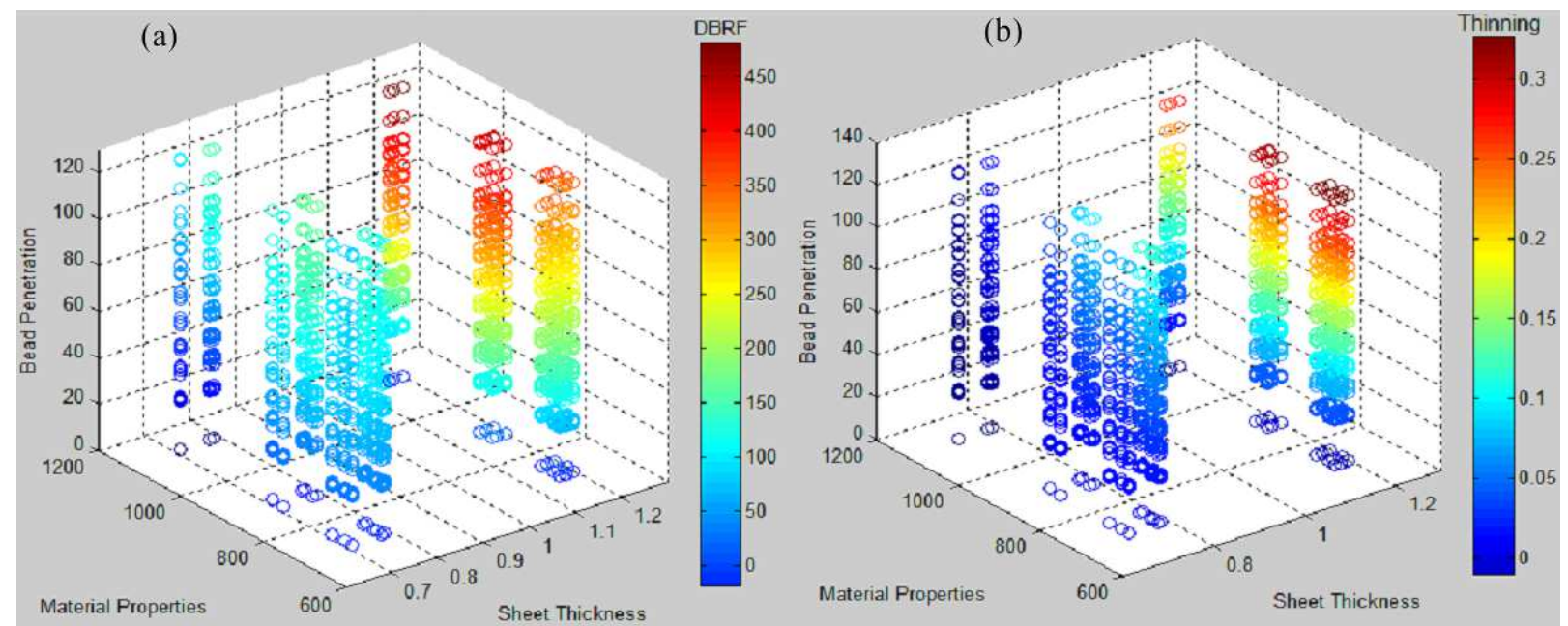

Fig. 2. The effects of sheet thickness, material properties and bead penetration on DBRF (a) and thinning (b).

computation-intensive problems in evaluating the sheet drawing characteristics. The method can also be applied to other sheet metal forming issue. Furthermore, a controller to obtain desired drawbead restraining force can be developed by using response surface model.

\section{References}

[1] M. Firat, Comp. Mater. Sci. 41, 266 (2008).

[2] H.D. Nine, Drawbead forces in sheet metal forming, Mechanics of sheet metal forming, Plenum Press, New York 1978.

[3] N.M. Wang, J. Appl. Metalwork 2, 193 (1982).

[4] N.M. Wang, V.C. Shah, J. Mater. Shaping Tech. 9, 21 (1991).

[5] M. Kojima, J. Jpn. Soc. Technol. Plast. 34, 1009 (1993).

[6] M.Y. Demeri, J. Mater. Eng. Perform. 2, 863 (1993).

[7] H. Sunaga, K. Yoneda, A. Makinouchi, NUMISHEET'96, Michigan USA, 1996, p. 186.
[8] Y.T. Keum, J.H. Kim, B.Y. Ghoo, Int. J. Solids Struct. 38, 5335 (2001).

[9] H. Naceur, Y.Q. Guo, J.L. Batoz, C. Knopf-Lenoir, Int. J. Mechanical Sciences 43, 2407 (2001).

[10] L.F. Han, G.Y. Li, X. Han, Z.H. Zhong, Inverse Probl. Sci. Eng. 14, 233 (2006).

[11] H. Livatyali, M. Firat, B. Gurler, M. Ozsoy, Mater. Design 31, 1639 (2010).

[12] G. Ingarao, R.D. Lorenzo, Comput. Struct. 88, 625 (2010).

[13] D. Wei, Z. Cui, J. Chen, Comp. Mater. Sci. 42, 228 (2008).

[14] D.E. Green, An experimental study of the effects of prestrain on formability limits, Industrial Research \& Development Institute, Midland-Ontario 2002.

[15] R.K. Verma, A. Haldar, J. Mater. Process. Tech. 190, 300 (2007). 